\title{
Violência, insegurança e imaginário do medo
}

\author{
Maria Cecília Sanches Teixeira* \\ Maria do Rosário Silveira Porto*
}

\begin{abstract}
RESUMO: O objetivo deste artigo é mostrar como a insegurança e o imaginário do medo, instalados na escola e tratados usualmente do ponto de vista do poder, com medidas restritivas e isoladoras, não são despertados somente pelo exercício e pela condição da violência cotidiana, mas por um "estado de violência" - ostensivo ou dissimulado - incorporado à cultura e ao imaginário individual e social. Ambos transformam as relações sociais, provocando a busca de novos lugares de encontro, socialidade, proteção. No cotidiano das escolas, precisam ser geridos por meio de práticas simbólicas e sociais diversas, que possibilitem lidar com essas novas relações.
\end{abstract}

Palavras-chave: insegurança, imaginário do medo, violência, rito, poder/ potência

Do rio que tudo arrasta se diz que é violento. Mas ninguém diz violentas as margens que o comprimem.

Bertold Brecht

\section{Introdução}

A insegurança no mundo moderno está cada vez mais ligada à ascensão da violência, que, por sua vez, promove a base e o fortaleci-

\footnotetext{
"Professora associada da Faculdade de Educação da USP e professora titular da Unip.

" Professora doutora da Faculdade de Educação da USP.
} 
mento de um imaginário do medo. Essas questões - insegurança, violência, medo - vêm ganhando realce nas discussões e produções atuais, na mídia, nas universidades, nas escolas, no cotidiano das pessoas, em virtude das conseqüências que originam e da aparente falta de controle de que se revestem.

No nível teórico, tais questões podem ser estudadas de diversos ângulos - social, econômico, político, psicológico, religioso, antropológico. Neste artigo, daremos realce a um tratamento sócio-antropológico, com base na teoria do imaginário de Gilbert Durand ${ }^{1}$, e fenomenológicocompreensivo, a partir da sociologia do cotidiano de Michel Maffesoli.

Inicialmente, vamos examinar algumas causas possíveis do desenvolvimento de um imaginário do medo nas sociedades modernas, cujas conseqüências podem estar influenciando o aumento da violência ou seu tratamento inadequado, ou, mesmo, estabelecendo condições que podem contribuir para o desenvolvimento desse imaginário. Em seguida, examinaremos a questão específica da dinâmica da violência. Finalmente, tentaremos colocar esses temas no quadro do cotidiano escolar, com vistas a buscar formas de gerir a insegurança no âmbito da escola.

O objetivo de nossa reflexão é, sobretudo, fornecer alguns subsídios para a discussão, tendo em vista a situação das escolas de nível fundamental e médio e de seus professores, cada vez mais atônitos com o nível de violência que vem transpondo os muros, do exterior para o interior da instituição escolar. Torna-se perceptível o fato de que a vida na escola vem se tornando cada vez mais difícil à proporção que a violência se desenvolve no seu interior e que, ao mesmo tempo, medidas de proteção são tomadas, mais e mais, contra a invasão de agressores externos, isolando-a paulatinamente do mundo que a cerca.

Assim, além de gangues, de traficantes, de ladrões e agressores que se postam fora dos muros escolares, a violência interna, provocada pelos próprios alunos, consubstancia-se em atos de indisciplina, quebra-quebras, brigas, depredações, que a escola não está mais conseguindo conter.

Afinal, o que está ocorrendo na sociedade? Na escola? Como compreender o fenômeno da violência que tanto nos assusta? Como encarar a insegurança e o medo que isso provoca? É disso que este artigo pretende tratar. 


\section{Imaginário do medo}

Dentre os fatores externos que, sem dúvida, contribuem para aumentar os níveis de violência na escola, lembramos as condições sócioeconômicas, os níveis cada vez mais absurdos de miséria e pobreza de uma camada da população que se elevam aceleradamente, a disseminação do uso de drogas entre os adolescentes, a psicologização da educação e a permissividade que ela gerou, o descompasso entre a escola e a tecnologia cada vez mais sofisticada deste final de século, a falta de equipamentos de esporte e lazer, na maior parte das cidades e dos bairros, destinados às crianças e aos adolescentes.

Nesse contexto, a violência é entendida como um saldo negativo e anacrônico de uma ordem bárbara que precisa ser controlada a qualquer preço ou como resposta a uma sociedade geradora de rejeições, de exclusões, expressão de xenofobia e de recusa do Outro (Balandier 1997, p. 212). Tal situação vem contribuindo para o desenvolvimento de um imaginário do medo, cujas conseqüências podem estar influenciando o aumento da violência ou seu tratamento inadequado.

Esse imaginário do medo, bem como sua concretização, tem suas raízes paradoxalmente fincadas, por um lado, numa crença infinita na razão, que pretende explicar o medo por meio do conhecimento científico e eliminar simultânea e gradativamente formas simbólicas de tratá-lo; por outro, num excessivo individualismo próprio do liberalismo moderno (selfmade man), que vem promovendo, cada vez mais, o distanciamento entre os indivíduos. Ambas as atitudes - racionalizadora e individualista têm como fundamentos justificadores e legitimadores uma visão etnocêntrica predominante, cujas conseqüências concretas são a marginalização e a exclusão do diferente, do Outro. ${ }^{2}$

Teixeira (1992), preocupada com o problema da marginalidade e da exclusão no que se refere à escola, colocou tais questões no âmbito da discussão sobre identidade e alteridade. Citando R. Dadoun (1985), um antropólogo francês, a autora discorre sobre o fato de que, para afirmar sua identidade, uma sociedade ou instituição cria a imagem do Outro. No caso da sociedade moderna, a razão ocidental desprende dela mesma partes irracionais para compor, no mesmo movimento, essa imagem do Outro e da sua própria identidade, essencialidade, normalidade. Ainda segundo Dadoun (apud Teixeira, op. cit.), a essa identidade racional contrapõem-se as três imagens de alteridade mais significativas do 
Ocidente - o louco, o selvagem e a criança -, às quais poderíamos acrescentar as do homossexual, do favelado, do migrante, do negro, enfim, todas aquelas que fogem à imagem ideal do homem ocidental, ariano.

Nesse sentido, continua a autora, todos os que não se enquadram nos padrões de normalidade vigentes são suspeitos; em decorrência, sofrem as conseqüências do estigma e da exclusão. Completaríamos a assertiva, lembrando que são criadas instituições para controlar, domesticar e reeducar o diferente: escolas de todos os tipos, reformatórios, prisões, asilos, manicômios etc., medidas que não fazem mais que alimentar o imaginário do medo.

$\mathrm{Na}$ modernidade, a violência tem sido considerada como uma das figuras reveladoras da desordem ${ }^{3}$ e da diferença que ela ameaça introduzir. Segundo Balandier (op. cit., pp. 207-212), a violência pode tomar a forma de uma desordem contagiosa, dificilmente controlável, de uma doença da sociedade que aprisiona o indivíduo e, por extensão, a coletividade num estado de insegurança que gera o medo. O medo, a catástrofe, o apocalipse freqüentam os palcos da modernidade como os veIhos monstros de retorno. Uma cultura de assombro (e um imaginário do medo) inscreve-se no corpo em movimento da cultura atual.

O imaginário do medo ocupa um espaço material no corpo, ou seja, tem uma inscrição corporal, porque, além de ser provocado por ameaças externas reais ou imaginárias, está associado, segundo G. Durand (1989), às imagens da angústia original devida à emergência da consciência do Tempo e da Morte, e às experiências negativas advindas dessa consciência. O desejo fundamental buscado pela imaginação humana é reduzir essa angústia existencial, através de seu princípio constitutivo que é o de representar, simbolizar as faces do Tempo e da Morte, a fim de controlá-las e às situações que elas representam.

Mas, em virtude da impossibilidade desse controle, ou seja, de distinguir e encarar o desconhecido e os perigos que ele pode representar, o imaginário cria imagens nefastas da angústia, expressas nos símbolos teriomorfos (da animalidade agressiva), nictomorfos (das trevas terrificantes) e catamorfos (da queda assustadora). Para enfrentá-las, o homem desenvolve duas atitudes imaginativas básicas, correspondentes a dois regimes de imagens: diurno e noturno.

No Regime Diurno, a representação permanece em estado de vigília, com as armas prontas para o combate. Tal atitude corresponde à estrutura heróica do imaginário, na qual os monstros, hiperbolizados, são com- 
batidos por meio de símbolos antitéticos: a espada ou a fuga (as trevas são combatidas pela luz e a queda pela ascensão). É evidenciada apenas a face trágica, o aspecto tenebroso e maléfico das faces do Tempo.

No Regime Noturno, o imaginário procura captar as forças vitais do devir, para poder exorcizar os ídolos mortíferos de Cronos. Combate a angústia existencial de duas maneiras: a) na estrutura mística, a face trágica do Tempo é minimizada pela negação ou pela inversão do valor afetivo a ele atribuído, pois a intenção é construir um todo harmonioso, onde a angústia e a morte não tenham lugar. Para isso, a imaginação utiliza a eufemização (a noite não é mais trevas nefastas, mas apenas sucessão do dia). O antídoto do Tempo é buscado na intimidade e no aconchego. b) na estrutura sintética, o drama temporal é desarmado de seus poderes maléficos pela busca de um fator de constância na fluidez do Tempo, pela incorporação, na sua inelutável movência, das securizantes figuras do ciclo (a noite é propedêutica necessária ao dia, promessa de aurora). Tal estrutura põe em jogo, alternadamente, as valorizações positivas e negativas do Tempo, evidenciando tanto a sua face trágica como a triunfante. Os aspectos ambíguos e simultâneos da realidade são percebidos e harmonizados.

Tem-se, pois, que o homem necessita representar o medo, atribuir significados comuns a situações, objetos e pessoas que causam temor. A representação é, em si, uma forma de controlar, antecipar, conhecer o medo. Pela representação, ele é partilhado e socializado, mas, ao mesmo tempo, é ampliado e estendido, e a conseqüência é que se deseja controlá-lo cada vez mais.

Acrescentem-se a essas causas naturais (bio/psicológicas) as situações sociais e culturais que geram insegurança, aumentando a angústia existencial e a necessidade de exorcizar o medo pela imaginação e podemos, então, avaliar o papel que o imaginário do medo exerce nas sociedades modernas.

Nessa perspectiva, Maria Milagros López (1988), pesquisadora da Universidad de Puerto Rico, considera o medo como uma condição transhistórica, uma qualidade social que emerge ou desaparece em função da relação real ou imaginária com o exterior. $O$ medo faz parte de nossa natureza, mas seus objetos são historicamente determinados, assim como as formas de organização social para combatê-lo. Constitui-se em realidade e representação, cujo fundamento empírico serve de base e de justificação para a constituição de um imaginário do medo. 
Segundo a autora, este opera como mediação simbólica entre o indivíduo e a sociedade, consolidando crenças, dúvidas, fantasmas, articulando-os em uma totalidade que guarda significações coletivas acumuladas e serve de guia para interpretar experiências. Ele é palpável em todos os aspectos da vida cotidiana e engendra formas subjetivas particulares. Seu impacto caracteriza-se por dois aspectos: 1) transforma as relações sociais, fazendo de cada indivíduo uma vítima atual ou potencial, ou um suspeito permanente, desenvolvendo formas de solidariedade e identificação ou colocando uns contra outros; 2) cria novos lugares de encontro, de socialidades ${ }^{4}$, originando aventuras comunitárias de proteção coletiva, que mobilizam os grupos em torno das figuras do medo.

Paradoxalmente, o imaginário do medo permite ao Estado medidas cada vez mais autoritárias, leis cada vez mais punitivas, legitimadas por demandas sociais de proteções reais e imaginárias, principalmente de alguns setores da sociedade, em especial, a classe média. Além disso, justifica atitudes como a legalização do porte de armas, a criação de empresas de segurança e o apoio à privatização da polícia. Cria, ainda, uma indústria de segurança - grades, seguros, alarmes - que, na maior parte das vezes, fornece mais proteção simbólica que real. Por fim, legitima discursos oficiais de políticos, da mídia, de chefes religiosos, de "personalidades" diversas, sobre o aumento da violência e da criminalidade como resultado de uma sociedade em decadência moral. Famílias desfeitas, liberação das mulheres, liberdade sexual, crise da ética do trabalho, crise da fé religiosa, crise moral são algumas causas citadas desse aumento.

Como resultado, tem-se, por um lado, o fortalecimento de um imaginário da ordem, justificando uma dominação institucional potencialmente infinita, uma diminuição dos espaços sociais, um "encarceramento" gradativo e voluntário das vítimas prováveis, cujos resultados podem servir como combustível para o crescimento e a continuidade do individualismo característico das sociedades modernas ou para a tribalização, para a organização de pequenos - e fechados - grupos, que, não raro, tomam o aspecto de gangues. Por outro lado, fortalecem-se, na vida cotidiana, as redes comunitárias de solidariedade, como tentativa de resistência à redução dos espaços de liberdade, pela fala das pessoas, mesmo que tais fenômenos possuam características conservadoras e paranóicas. Essa fala consubstancia-se em uma narração sobre o medo, criada e recriada coletivamente, que pressupõe a existência - ou preexistência - de um imaginário interiorizado, que porta noções sobre procedimentos, sentimentos, tipos de vítimas etc. 
Em seu texto, López cita Ackerman, Dulong e Jeudy, que observaram, em suas pesquisas sobre o imaginário da segurança, que há uma grande uniformidade nos relatos, tanto das pessoas que foram vítimas de atos violentos como daquelas que não o foram. Elas interiorizam representações do que acontece no caso de violência, quais os sentimentos e a conduta da vítima e suas reações. O mecanismo de base é, pois, a identificação com a vítima e a reapropriação do incidente, o que gera uma socialidade da insegurança, pela qual, solidariamente, antecipamos a nossa vitimização futura. Por isso, a insegurança precisa ser abordada muito mais como um discurso já rigorosamente articulado do que como um objeto.

Cada ação concreta de agressão ou violência permite ritualizar uma ameaça, justificando a reprodução do medo e a adoção de medidas de segurança. Mas, paradoxalmente, essas medidas acentuam a insegurança e o medo e provocam novas formas de geri-los, seja na sociedade, seja na escola.

Em conclusão, podemos inferir do texto de Milagros que: 1) o imaginário do medo é alimentado por dados reais ou imaginários; 2) o medo consubstancia-se em objetos historicamente determinados; 3) ao mesmo tempo em que o imaginário do medo coloca todos contra tudo, estabelece uma rede de relações que fortalece a solidariedade e a socialidade entre os membros do grupo, que se unem pelo sentimento comum de insegurança; 4) a insegurança e o medo, reais ou imaginários, provocam novas medidas de segurança, que, paradoxalmente, reproduzem-se em novas bases.

\section{A dinâmica da violência}

Maffesoli $(1978,1981,1987)$ trata a violência do ponto de vista do seu dinamismo interno, como herança comum a todo e qualquer conjunto civilizacional, estruturando constantemente a vida em sociedade. Constitui-se em força e potência, motor principal do dinamismo social, que remete ao confronto e ao conflito. A luta é o fundamento de toda relação social e se manifesta em instabilidade, espontaneidade, multiplicidade, desacordos, recusas.

O autor lembra que, embora todas as coletividades históricas sempre tenham a preocupação de controlar a violência, nas sociedades modernas esse controle pretende-se absoluto. O uso da força física tem sido monopolizado pela organização política e pelos poderes instituídos, que, 
sob a aparência de neutralidade, exercem, legalmente, uma violência abstrata: centralizando tudo o que é da ordem do policial, do militar e do fiscal, tentam estabelecer uma normalidade asséptica, domesticando a paixão e a agressividade.

Esse processo de racionalização é acompanhado de uma potencialidade irracional. A violência monopolizada pretende ser sua própria negação, conduzindo a uma ideologia da "tranqüilização da vida social". No entanto, dada sua potencialidade, a violência pede um certo grau de socialização e de acordo, que nas sociedades primitivas se dava, sabiamente, por mecanismos de ritualização, permitindo que, de algum modo, ela fosse exteriorizada. A consciência de que a violência não pode ser eliminada deveria provocar uma atitude de astuta negociação, com o intuito de "amansá-la", socializá-la.

Segundo Balandier (op. cit., p. 208), nas sociedades tradicionais, a violência está sempre presente, sempre a postos e sob controle: do homicídio (não reprovado quando é sancionado) aos confrontos internos entre grupos e à guerra (orientada para o estrangeiro, inimigo real ou potencial); da violência formadora, meio de educação e socialização de adolescentes, à oculta, insidiosa, que toma a forma de feitiçaria, ou aberta, jamais inteiramente contida. Ela é domesticada, tratada ritualmente, como forma de prevenir-se contra a sua subversão ou perturbação.

Nas sociedades modernas, ainda segundo o autor (p. 211), ao lado da manutenção das formas conhecidas de violência - que atualizam o delinqüente, o criminoso, o rebelde, o herói combatente -, novas formas surgem, ligadas a condições sociais e culturais inéditas e inconstantes. Com isso, são ampliadas tanto a sua visibilidade quanto a consciência de sua existência. Mas, diferentemente do que ocorre nas sociedades tradicionais, nas modernas, o monopólio e a racionalização da violência conduzem, de um lado, ao desencadeamento que nada consegue reprimir, conforme atesta o aumento gradativo da criminalidade e da insegurança urbana, e, de outro, à interiorização das normas.

Com isso, impede-se a expressão dos antagonismos próprios de todo corpo social e promove-se, simultaneamente, a homogeneização da sociedade. Além disso, ao se desconsiderar a sua essência ritualística, ao particularizá-la "(...) o que é a luta de todos contra os outros tende a se fragmentar em luta de cada um contra todos, pequena guerrilha fundada na atomização que faz com que a violência se dilua em agressividade mesquinha e cotidiana" (Maffesoli 1987, p. 19). 
De modo geral, a violência é tratada a partir do ponto de vista do poder, portanto, da lógica da dominação, que consegue - ou não - ser eficaz na sua repressão, desconsiderando-se a coletividade na qual se manifesta a potência ${ }^{5}$. Entretanto, é no embate entre poder e potência que emergem as diferentes modalidades da violência, das quais Maffesoli analisa três: a totalitária, a anômica e a banal.

A violência totalitária resulta do monopólio de uma estrutura dominante - Estado, partido, organização criminosa ou terrorista - que impõe uma planificação e um controle monopolizado: domesticação das paixões e da agressividade, coerção, anonimato que levam ao tédio, à monotonia da equivalência generalizada. Como exemplo, podemos citar a burocracia que, no limite, encarna a supremacia do individualismo e a tentativa de destruir a coesão social, inclusive as formas de ritualização da violência construídas pelos grupos sociais.

Entretanto, para Maffesoli, há uma permanente tensão entre poder e potência ${ }^{6}$ pois, mesmo que aparentemente a massa ou o grupo se submeta ao poder, só o faz enquanto não houver possibilidade de confronto. Nos momentos de efervescência (revoluções, greves), a potência eclode e esse confronto torna-se possível. Quando um dos pólos da relação poder-potência é bloqueado, rompe-se o equilíbrio; nesses momentos, dá-se a manifestação perversa da potência, que explode em violência generalizada. A tentativa de controle absoluto é exemplo desse rompimento.

Esse tipo de violência é chamada por Maffesoli (1981) de anômica. Ela é uma resposta à violência e à dominação dos poderes instituídos, no intuito de proteger o corpo social. Manifesta-se em atos de resistência e nas diversas formas de ilegalidade e consubstancia-se em revoltas latentes que explodem ocasionalmente. É um fenômeno ambivalente que se inscreve num duplo movimento - de destruição e reconstrução -, que mantêm uma estreita conexão entre si, constituindo um vaivém incessante entre ordem e desordem, fundamento da estruturação social. Essa violência precisa ser ritualizada para se integrar harmoniosamente; se for reprimida ou negada, explode em crueldade ${ }^{7}$.

A relação poder/potência será sempre dialética, porque nesses momentos um novo poder se instala e o ciclo recomeça. E poder sempre será imposição, pois, como diz Maffesoli (apud Teixeira 1990, p. 80), ele não muda de natureza quando muda de mãos. Há, entretanto, uma lógica própria nos processos de ritualização da violência, como, por 
exemplo, os casos de linchamento, as guerras de gangues, de traficantes etc. Nesse sentido, a violência anômica é fundadora, pois exprime a capacidade da sociedade de estruturar-se coletivamente, quando assume e controla sua própria violência. Nunca é absolutamente desenfreada, porque sempre acaba entrando num processo de negociação, de adaptação.

Mas, há uma outra forma de violência que a coletividade utiliza para fazer frente às formas de dominação: a banal. Esta expressa uma passividade (ativa) da massa que não se integra ao instituído, mas se opõe a ele, subvertendo o poder, embora sem integrar qualquer contestação ou ação política. Submissões aparentes, conformismo, por exemplo, são formas de resistência, de expressão da duplicidade: não há recusa absoluta, nem adesão arrebatada. Não se luta contra os valores estabelecidos, antes, procura-se manter distância ou utilizar formas de resistência, como a arte de fachada, zombaria, ironia, comicidade, polidez, máscara, silêncio, palavra (tagarelice), grafites e pichações.

Entretanto, não são propostos valores para substituir os oficiais. Tais atitudes, subversivas, expressam, segundo Maffesoli (1985), um imoralismo ético ${ }^{8}$ das massas, que permite a partilha de sentimento, o querer-viver social, o estar-junto, o aqui e agora, o presenteísmo.

\section{A violência e a insegurança na escola}

$\mathrm{Na}$ instituição escolar, um problema de difícil solução, segundo opinião geral, é a questão da insegurança, decorrente dos níveis de violência presentes dentro e fora da escola. Como foi dito inicialmente, professores, pais e alunos de escolas de ensino básico estão cada vez mais atônitos com o nível de violência extra e intramuros. Nem muros, nem grades, nem vigias ou guardas parecem deter a violência externa; medidas disciplinares, igualmente, são inócuas para resolver atos cada vez mais violentos de indisciplina que eclodem em seu interior.

Tal como na sociedade, na escola as situações potencialmente geradoras de violência são permanentes, e não apenas conjunturais. Para Balandier (op.cit., p. 212), o meio social, em seus movimentos e configurações, deixa passar a ação violenta, aumentando e fortalecendo o temor pela incerteza e provocando ondas de medo, tal como ondas de febre. 
A escola vive hoje o que Figueiredo (1996) chama de "estado" ou "condição" de violência, algo que passa a constituir um ingrediente permanente da cultura (no caso, da cultura escolar), marcando um regime de sociabilidade dominante. Em outras palavras, o imaginário do medo tem produzido nas escolas o que podemos chamar de "cultura da violência", entendendo cultura como teia de significados tecida pelo homem e na qual ele se enreda (Geertz 1989).

Guimarães (1996), em pesquisa realizada em escolas públicas da cidade de Campinas, aponta-nos manifestações dessa cultura da violência, em suas diferentes modalidades, no cotidiano escolar, tanto do ponto de vista do poder (violência dos poderes instituídos, utilitária) quanto do da potência (alunos e professores discordantes). À violência institucional em suas diferentes modulações - aulas "duplas", cópias, ditados (segundo os docentes, a única forma de manter os alunos em silêncio), discriminações e exclusões de naturezas diversas -, os alunos respondiam com explosões de ilegalidade: depredações, pichações, brigas entre si ou com professores e funcionários, xingamentos. Já os professores discordantes procuravam, a partir da compreensão do vivido pelo aluno, criar práticas alternativas que permitissem não o controle da violência, mas sua aceitação e sua ritualização (p. 91).

A autora mostra que domesticar a violência por meio de regras e códigos de conduta rígidos parece não ser a solução. O desafio é canalizá-la, organizá-la, integrá-la a e combiná-la com outras práticas sociais e simbólicas da escola. Trata-se, em outras palavras, de procurar formas de geri-la enquanto figura da desordem, já que nenhuma sociedade pode ser purgada de toda desordem. É preciso, então, saber lidar com ela, em vez de tentar eliminá-la.

Este é, fundamentalmente, o papel do rito ${ }^{9}$ : tratar a desordem no sentido de lhe dar uma forma dominável, de convertê-la em fator de ordem ou de deportá-la para os espaços imaginários. Segundo Balandier (op. cit., p. 36), por meio de procedimentos, nos quais operam, principalmente, a transgressão e a inversão, o mito e o rito tornam-se os instrumentos que permitem juntar ordem e desordem, do mesmo modo que a Grécia antiga associava medida e desmando, razão e excesso dionisíaco.

Para Bernstein (1971, p. 276):

(...) a função simbólica dos ritos humanos é religar os indivíduos, atra- 
vés dos atos rituais, à ordem social; de revivificá-la no seio dos indivíduos e em particular reforçar neles sua aceitação dos métodos utilizados para manter a continuidade, a ordem e a fronteira social; enfim de controlar a ambivalência do indivíduo frente à ordem social.

Em outras palavras, ao transmitir uma visão de mundo e códigos culturais, os ritos servem como dispositivos de moldura que permitem aos participantes localizar-se na sociedade e na cultura de seu tempo, garantindo, com isso, a construção da identidade grupal.

No entanto, o que se percebe hoje é que a escola vem sofrendo um processo de empobrecimento dos rituais que garantiriam a construção de sua identidade e das identificações de seus diferentes grupos. A progressiva desritualização da escola decorre, no nosso entender, do enfraquecimento dos sistemas de valores da sociedade e da escola, em torno dos quais se estruturavam tais identificações: ao se enfraquecer tornaram-se ambíguos, e a ritualização que eles promoviam também empobreceu.

Nesse sentido, assiste-se a uma passagem da predominância dos ritos criados pela escola para a dos ritos criados e dirigidos pelos alunos, que, muitas vezes, expressam-se em atos considerados violentos ${ }^{10}$ : ao "imaginário da ordem", os alunos contrapõem um "imaginário da transgressão" ou "do conflito".

Daí ser imprescindível à escola retomar o processo de ritualização. É preciso que ela recrie e preserve seus rituais, em especial aqueles que desenvolvem e fortalecem o "cimento" grupal, incluindo-se cerimônias diversas, jogos, disputas e campeonatos esportivos, os quais podem contribuir para ritualizar a violência e a desordem, e para explorar potencialidades em favor de uma nova ordem/desordem.

As soluções devem ser encontradas em cada escola ou em cada sala de aula, para cada caso. Entretanto, é possível apontar algumas, tendo em vista as questões trabalhadas neste texto e relatos de experiências que vêm tendo êxito em várias instituições escolares.

Uma medida que parece surtir bom efeito é a aproximação gradativa da escola com a comunidade, por intermédio de várias atividades de integração, num sistema de parceria em que a instituição supre, de alguma forma, as carências de espaço e de equipamentos sociais, e a população "cuida" da escola, desde a vigilância até a realização de pequenos consertos; integra voluntariamente órgãos colegiados, como o Conselho de Esco- 
la e a Associação de Pais e Mestres; provê assistência de toda ordem às crianças carentes; enfim, passa a participar ativamente da instituição escolar.

Além disso, há outras medidas que podem "reencantar" a escola, tais como: desenvolver atividades de lazer e de cultura, tais como excursões a museus, parques florestais e zoológicos; levar os alunos para assistir a espetáculos teatrais, filmes etc.; promover e dar espaço a grupos de alunos e professores interessados em trabalhar com teatro, música, jornal; realizar exposições de arte, oficinas de criação, feiras de ciência; "enfeitar" a escola com produções de alunos (pinturas, redações, trabaIhos escolares diversos); encontrar espaços para os alunos trabalharem a terra (jardim, horta); abrir possibilidades de tempo e espaço para que os alunos possam "jogar conversa fora", brincar, "paquerar", enfim "estar juntos" etc.

Enfim, não se pode desprezar, porque desconhecidas (ou não reconhecidas) pelas instâncias dominantes, as pequenas ações de todos os dias, desenvolvidas pelos membros dos diversos grupos da escola (professores, alunos e funcionários) dentro ou fora da sala de aula, que, pela carga simbólica e, portanto, educativa que carregam, contribuem para o desenvolvimento de uma ética grupal (conforme a entende Maffesoli), ou seja, para o reconhecimento da instituição, quanto a sua cultura e seu imaginário.

\section{Notas:}

1 O termo "imaginário" é utilizado neste artigo com um dos sentidos que Ihe atribui Gilbert Durand (1989), como "(...) conjunto de imagens e de relações de imagens que constituem o capital pensado do homo sapiens" (p. 41).

${ }^{2}$ De acordo com Paula Carvalho (1997), “(...) o etnocentrismo consiste em privilegiar um universo de representações, propondo-o como modelo e reduzindo à insignificância os demais universos e culturas diferentes" (p. 181).

${ }^{3}$ Para Balandier (op. cit., p. 11), a desordem é um conceito importante para se compreender a sociedade moderna, na qual predominam o movimento e a incerteza. O movimento se realiza em múltiplas formas, vistas por muitos como armadilhas ou como máscaras da desordem. Considerando que ordem e desordem são duas faces da mesma moeda e que se referem sempre à relação do todo e das partes nos conjuntos de elementos e nas sociedades, o autor assim as define: "Existe 'ordem' quando os elementos não existem sem ligação, mas têm entre si um princípio de unidade que os faz participar, ao 
mesmo tempo, de um conjunto único (...). Existe desordem quando os elementos de um conjunto, fazendo parte desse todo, comportam-se como se não fizessem parte" (p. 47). A desordem é, geralmente, vista sob o aspecto do mal ou do inesperado, do incomum. Por isso, todas as sociedades reservam um lugar para ela, mesmo temendo-a; por não terem a capacidade de eliminá-la, precisam encontrar formas de compor-se com ela (p. 121). No entanto, a modernidade parece atribuir-Ihe uma capacidade de onipresença e de crescente virulência, transformando-a na principal referência obsedante e fixadora de incompreensões, inquietudes e angústias (p. 194).

4. Maffesoli entende a socialidade como a experiência social compartilhada pela multiplicidade das redes formadas por pequenos grupos no cotidiano. $\mathrm{O}$ autor a utiliza para significar o "estar junto", que supera a simples associação racional, usualmente expressa pelo termo social.

5. Segundo Maffesoli (1981, pp. 45 e 50), a potência é uma pulsão, no sentido simples do termo, que se expressa em todos os níveis da existência individual e social. Enquanto a lógica do poder é a dominação, a redução ao uno, a lógica da potência conduz ao pluralismo, à diversidade do real que estrutura inteiramente a vida social em sua labilidade.

6. Podemos dizer, com Balandier (op. cit., p.48), que este duplo movimento da violência corresponde às duas figuras da desordem: a destruidora, quando ocorre perda da ordem e os elementos se dissociam e tendem a não mais constituir uma estrutura, uma organização, mas uma adição, uma simples soma; e a criadora, quando essa perda é acompanhada de um ganho de ordem, é geradora de uma nova ordem que substitui a antiga, em um nível mais elevado.

7. De uma outra perspectiva que corrobora esta, Figueiredo (1996) diz que, se há condições de violência excessiva e destrutiva, há, também, e em qualquer cultura, uma prática inevitável - e até indispensável - de violência estruturante e constitutiva de subjetividade.

8. De acordo com Maffesoli (1985, p.22), o imoralismo ético é a sólida e subterrânea consciência que o corpo coletivo tem de si próprio. Diferentemente da moral que se refere a um único valor de uma determinada ordem estabelecida, a ética remete ao equilíbrio e à relativização recíproca dos diferentes valores que integram um conjunto social. Contribui para conservar, de maneira astuta e encarniçada, uma multiplicidade de atitudes consideradas aberrantes pela moral da época.

9. O rito é aqui entendido como um processo que envolve a encarnação de símbolos e de constelações de símbolos, por meio de gestos corporais formativos. É também, encarnação de estados interiores cognitivos, afetivos e imaginários, através dos quais o homem busca a transcendência (Teixeira, 1997, p.7).

10. Ao comentar as relações entre adolescência e violência, Figueiredo (op. cit.) mostra que estas podem ser tratadas em diversos níveis, que devem repousar na aceitação de que há uma violência salutar - desafiadora, intempestiva, 
irresponsável, lúdica, provocadora, criativa e, frequentemente transgressora

-, decorre da imaturidade do adolescente.

\title{
Violence, unsecurity and "imaginary of fear"
}

\begin{abstract}
In the set of actions which define the dimension of politics, departing from the act of interpreting, explaining, and controlling the urban violence phenomenon, it is intended to conduct the contemporaneous way of making, which we may call negotiating with school depredation. This article focuses on reflections on studies and researches carried out in Brazil and France on the urban violence uprising in schools located in poor and unfortunate regions.
\end{abstract}

\section{Bibliografia}

BALANDIER, Georges. A desordem: Elogio do movimento. Rio de Janeiro: Bertrand Brasil, 1997.

BERSTEIN, Bernard. "Les rites dans l'éducation". In: HUXLEY, Julian. Le comportament rituel chez l'homme et l'animal. Paris: Gallimard, 1971.

DADOUN, Roger. "Mais quel Occident? Quels autres?" En Marge: l'Occident et ses "autres". Colloque de Rome, 1985, pp. 11-21.

DURAND, Gilbert. As estruturas antropológicas do imaginário. Lisboa: Presença, 1989.

FIGUEIREDO, Luis Cláudio. "Adolescência e violência: Considerações sobre o caso brasileiro". Comunicação apresentada no II Encontro "Adolescência e violência. Conseqüências da realidade brasileira”, São Paulo, 1996 (mimeo.).

GEERTZ, Clifford. A interpretação das culturas. Rio de Janeiro: LTC, 1989.

GUIMARÃES, Áurea Maria. A dinâmica da violência escolar: Conflito e ambigüidade. Campinas: Autores Associados, 1996.

LÓPEZ, Maria Milagros. "Notre peur de tous les jours: L'imaginaire de l'insecurité et la militarisation de la vie quotidienne à Porto Rico". 
Comunicação apresentada no Colloque International de Sociologie de la Vie Quotidienne. Paris: Sorbonne, Université René Descartes, 1988 (mimeo.).

MAFFESOLI, Michel. Lógica da dominação. Rio de Janeiro: Zahar, 1978. . A violência totalitária, ensaio de antropologia política. Rio de Janeiro: Zahar, 1981.

A sombra de Dionísio, contribuição a uma sociologia da orgia. Rio de Janeiro: Graal, 1985.

A dinâmica da violência. São Paulo: Ed. Revista dos Tribunais, 1987.

MARTINS, José de Souza. "Linchamentos: A vida por um fio". Travessia - Revista do Migrante. Publicação do CEM, ano II, no 4, maio/agosto 1989 , pp. 21-24.

PAULA CARVALHO, José Carlos. "Etnocentrismo, inconsciente, imaginário e preconceito nos universos das organizações educativas". Botucatu, revista Interface: Comunicação, Saúde e Educação, vol. 1, no 1, pp. 181-185, 1997.

TEIXEIRA, Maria Cecília Sanchez. Antropologia, cotidiano e educação. Rio de Janeiro: Imago, 1990.

. "Escola, exclusão e representação". São Paulo, Revista da Faculdade de Educação, v. 18, no 1, 1992, pp. 20-32.

. "Cultura escolar: Os ritos enquanto práticas simbólicas organizadoras do espaço-tempo do grupo". Palestra proferida no curso de pós-graduação em Educação da UFF, 1997. 